http://dx.doi.org/10.21707/gs.v10.n01a17

\title{
Cientistas Ambientais: aCADÊMicos ou Ambientalistas PROFissionais?
}

\section{Christiana Profice; ${ }^{1}$ Salvador Trevizan ${ }^{2}$; Alexandre Schiavetti ${ }^{3}$ \& Fabio Massena ${ }^{4}$}

\author{
'Professora TitularProdema-UESC Dra. Psicologia Social e líder do Grupo de Pesquisa em Interações Socioambientais. E-mail: ccprofice@uesc.com.br \\ ${ }^{2}$ Professor Titular Prodema-UESC.E-mail:salvador@uesc.br \\ ${ }_{3}^{3}$ Bolsista de produtividade CNPq, pesquisador associado aos Projetos CoralVivo e Golfinho Roteador, Coordenador local Doutorado em Associação em Desenvolvimento e Meio Ambiente (Biênio \\ 2014-2016).E-mail:aleschi@uesc.com.br \\ ${ }^{4}$ Professor Adjunto UESC, Doutorado em Desenvolvimento de Meio Ambiente (UESC) Tem experiência em projetos ambientais e agropecuários. E-mail:fabiomassena@gmail.com
}

Recebido em 06 de setembro de 2015. Aceito em 28 de dezembro de 2015. Publicado em 30 de junho de 2016.

REsumo - A formação em ciências ambientais nos programas de pós-graduação stricto sensu pode atender tanto a propósitos acadêmicos como a expectativas de intervenção profissional. Buscamos participar desse debate por meio da análise do Mestrado em Desenvolvimento Regional e Meio Ambiente da Universidade Estadual de Santa Cruz (MDRMA/UESC), localizado em Ilhéus na região sul do Estado da Bahia e parte de uma rede mais ampla, o Programa Regional de Pós-Graduação em Desenvolvimento e Meio Ambiente (PRODEMA). Para tal fim iniciamos com uma breve demarcação teórica acerca das interpelações entre meio ambiente, desenvolvimento, interdisciplinaridade e ciências ambientais pautada nas definições de critérios de área conforme os documentos da CAPES, bem como na apresentação de reflexões atuais sobre o tema na literatura. Reconstruímos a trajetória histórica do MDRMA/UESC e de suas avaliações pela CAPES. Em seguida apresentamos e discutimos os dados obtidos a partir da análise dos perfis de egressos e suas publicações. Em posse destes dados e de demais informações acerca do MDRMA/UESC aplicamos a matriz SWOT para apreciarmos seus pontos fortes, suas fragilidades, bem como suas oportunidades e ameaças. Ao final tecemos considerações acerca do tema proposto e analisamos diferentes cenários para o futuro do MDRMA/UESC. Palavras-Chave: Ciências ambientais, Interdisciplinaridade, Pós-Graduação, Desenvolvimento.

\section{ENVIRONMENTAL SCIENTISTS: ACADEMIC OR PROFESSIONAL ENVIRONMENTALISTS?}

ABstract - Postgraduate programs in environmental sciences can meet both academic purposes such as professional intervention expectations. We analyze the Master Program on Regional Development and Environment of the State University of Santa Cruz (MDRMA / UESC), located in Ilhéus in the southern region of Bahia, part of a wider regional network, the Regional Program of Graduate Studies in Development and Environment (PRODEMA). To achieve this goal we start with a brief theoretical demarcation about interpolations between environment, development and interdisciplinary in environmental sciences. We reconstructed the historical trajectory of MDRMA / UESC and their ratings by CAPES to present and discuss the data obtained from the analysis of the graduates' profiles and their publications. We also apply the SWOT matrix to appreciate their strengths, weaknesses, opportunities and threats. At the end we weave some considerations about the proposed theme and analyze different scenarios for the future of MDRMA / UESC.

Key Words: ENVIRONMENTAL SCIENCES, INTERDISCIPLINARY, MASTER PROGRAM, DEVELOPMENT

\section{LOS CIENTÍfICOS AMBIENTALES: AMBIENTALISTAS ACADÉMICOS O PROFESIONALES?}

Resumen - La formación en ciencias del medio ambiente en los programas de postgrado puede cumplir tanto con fines académicos como las expectativas de intervención profesional. Proponemos el análisis del Máster de Desarrollo Regional y Medio Ambiente de la Universidad del Estado de Santa Cruz (MDRMA / UESC), con sede en Ilheus, Bahia, y parte de una red regional más amplia, el Programa Regional de Estudios de Posgrado en Desarrollo y Medio Ambiente (PRODEMA). Para ello partimos de una breve delimitación teórica sobre interpolaciones entre el medio ambiente, el desarrollo, y la interdisciplinariedad. Hemos reconstruido la trayectoria histórica de MDRMA / UESC y sus calificaciones por CAPES. Presentamos y discutimos los datos obtenidos a partir del análisis de los perfiles de los graduados y sus publicaciones. Aplicamos la matriz SWOT para apreciar sus fortalezas, sus debilidades sus oportunidades y sus amenazas. Presentamos nuestros comentários finales sobre el tema propuesto y analizamos diferentes escenarios para el futuro de MDRMA / UESC.

Palabras Clave: Ciencias ambientales, Interdisciplinariedad, Máster, Desarrollo

\section{INTRODUÇão}

A formação em ciências ambientais nos programas de pósgraduação stricto sensu pode atender tanto a propósitos acadêmicos, por meio de pesquisas acerca dos problemas ambientais, como a expectativas de intervenção profissional nos contextos reais em que estes problemas se apresentam. Esta discussão apresenta questões conceituais importantes, mas também implica em consequências práticas para os cursos que se encaixam na temática ambiental. Neste trabalho pretendemos participar deste debate, tanto em seus aspectos mais teóricos como na análise de seus desdobramentos práticos no Mestrado em Desenvolvimento Regional e Meio Ambiente da Universidade Estadual de Santa Cruz (MDRMA/UESC), localizado em Ilhéus na região sul do Estado da Bahia e parte de uma rede regional mais ampla o Programa Regional de Pós-Graduação em Desenvolvimento e Meio Ambiente (PRODEMA), do qual atualmente participam cursos similares de cinco universidades federais (UFAL, UFC, UFPB, UFPI e UFS) e três estaduais (UERN, UEPB e UESC) do Nordeste do Brasil. O que motivou nossa análise foi a recente transição dos cursos credenciados ao PRODEMA da Área Interdisciplinar (AI) para a de Ciências Ambientais (ACA). Em uma avaliação interna de sua história do perfil de egressos do MDRA/UESC e de suas publicações verificamos que esta passagem de uma área para outra significou uma queda de pontuação no sistema de periódicos qualis da Coordenação de Aperfeiçoamento de Pessoal de Ensino Superior (CAPES) vinculada ao Ministério da Educação (MEC).

Nesta direção nosso artigo inicia com uma breve demarcação teórica acerca das interpelações entre meio ambiente, desenvolvimento, interdisciplinaridade e ciências ambientais pautada nas definições de critérios de área em documentos da CAPES, bem como na apresentação de reflexões atuais sobre o tema na literatura. As expectativas referentes a criação da ACA também ilustra os dilemas conceituais e práticos vivenciados pelos programas de pósgraduação em meio ambiente, especialmente aqueles que fazem parte do PRODEMA. Reconstruímos também a trajetória histórica do MDRMA/UESC e de suas avaliações pela CAPES. Em seguida apresentamos e discutimos os dados obtidos a partir da análise dos perfis de egressos e suas publicações. Em posse destes dados e de demais informações acerca do MDRMA/UESC aplicamos a matriz SWOT para apreciarmos seus pontos fortes, suas fragilidades, bem como suas oportunidades e ameaças. Ao final tecemos considerações acerca do tema proposto e analisamos diferentes cenários para o futuro do MDRMA/UESC além de buscar responder à questão 
inicial lançada no título de nosso trabalho: afinal estamos formando acadêmicos ou ambientalistas profissionais?

\section{InterdiciplinARIdAde E CiênCIAs Ambientais - aspectos CONCEITUAIS E PRÁTICOS}

Em 1998, a área de conhecimento Multidisciplinar foi criada pela CAPES e a partir de 2008, foi designada como Área Interdisciplinar (AI). Seu objetivo era agregar cursos de pós-graduação com caráter interdisciplinar que tinham seu foco em questões complexas que nem sempre encontravam representação em áreas mais específicas (CAPES, 2013a). Dado o enorme volume de cursos abrigados nesta área, em 2004, foram criadas quatro Câmaras Temáticas, a saber, Câmara I - Meio Ambiente \& Agrárias; Câmara II - Sociais \& Humanidades; Câmara III - Engenharia, Tecnologia \& Gestão; e Câmara IV - Saúde \& Biológicas. Em 2011 a Câmara I foi desmembrada e passou a constituir uma nova área, a Área de Ciências Ambientais (ACA).

Durante o processo de criação da ACA em 2011, houve a expectativa, por parte dos cursos do PRODEMA, de que enfim deixavam de perambular sem-teto no mundo acadêmico, buscando algum nicho preexistente no qual se encaixar. Suas produções (projetos e publicações) eram frequentemente inseridas na área de Biologia e Ecologia, geralmente identificadas como a casa de pertencimento da produção científica sobre meio ambiente. Podemos dizer que naquela condição os programas como do PRODEMA viviam sob o domínio do biocentrismo acadêmico que considera como legítimas aquelas pesquisas que, de modo bem direto, se voltam para a preservação dos biomas brasileiros e de seus recursos. Nesse contexto, as investigações e intervenções socioambientais viviam desamparadas porque eram avaliadas por critérios biocêntricos ou, por outro lado, nas Ciências Sociais e Humanas, não havia o reconhecimento da dimensão ambiental nos paradigmas tradicionais dessas áreas, nas quais as relações humanas/sociais se davam, supostamente, num universo abstrato. Quando, finalmente, foi aprovada a ACA, no dia do meio ambiente, em cinco de junho (CAPES, 2013b), os coordenadores dos cursos do PRODEMA vibraram com a expectativa de que se livrariam da condição de sem teto acadêmico. A inclusão na ACA foi unânime, parecia um alívio e a perspectiva de novas esperanças, houve inclusive a consulta a respeito dos periódicos adequados para a formação da lista qualis da área. Aos poucos, entretanto, ficou claro que aqui as produções no campo socioambiental não eram bem avaliadas, tendo poucos periódicos com qualis elevado (A1 e A2), comparando com outras áreas do conhecimento, especialmente, das Ciências Naturais, trazendo para a nova área sua herança biocêntrica.

Atualmente a AI se organiza da seguinte forma: Câmara I - Desenvolvimento \& Políticas Públicas; Câmara II - Sociais \& Humanidades; Câmara III - Engenharia, Tecnologia \& Gestão; e Câmara IV - Saúde \& Biológicas. No mesmo ano de criação da ACA, se deu a criação das áreas de Nutrição e de Biodiversidade, esta última a partir da Área de Ecologia e Meio Ambiente que foi extinta. Conforme documento da CAPES (2013a), "entende-se por Interdisciplinaridade a convergência de duas ou mais áreas do conhecimento, não pertencentes à mesma classe, que contribua para o avanço das fronteiras da ciência e tecnologia, transfira métodos de uma área para outra, gerando novos conhecimentos ou disciplinas e faça surgir um novo profissional com um perfil distinto dos existentes, com formação básica sólida e integradora” (p.12). Desse modo, a AI pretende abrigar os pesquisadores e suas investigações que superem as fronteiras disciplinares e proponham novas soluções teóricas e práticas para os problemas científicos contemporâneos. Ela traz em si a ideia de que o profissional especialista encontra limitações diante de problemas complexos que implicam necessariamente em uma abordagem interdisciplinar, conduzida por cientistas que além de dominarem os desafios de sua própria área de formação sejam capazes de integrar e articular conhecimentos oriundos de outros campos do saber em suas pesquisas. Ser dotado da habilidade de comunicação com distintas áreas do conhecimento e da capacidade de integrar seus resultados e assim avançar cientifica e tecnologicamente, este é o perfil do cientista interdisciplinar. Em outras palavras, interdisciplinaridade não é uma área de conhecimento, mas é um estado de espírito, de abertura da mente, de predisposição para interagir com diferentes áreas do conhecimento, sejam elas quais forem.

A ACA se organizou a partir da "necessidade de se dar conta dos problemas ambientais, face à indissociabilidade entre sistemas antrópicos e naturais que emergem no mundo contemporâneo, muitas vezes decorrente do próprio avanço dos conhecimentos científicos e tecnológicos, baseados em uma construção do saber notadamente disciplinar. A natureza complexa da problemática ambiental pede diálogos não só entre disciplinas próximas, dentro da mesma área de conhecimento, mas entre disciplinas de ciências diferentes, bem como com outras formas de saberes, oriundos de culturas heterogêneas" (CAPES, 2013b). O documento enfatiza que o caráter interdisciplinar é intrínseco à ACA que não pretende ser apenas uma justaposição de ciências humanas, da terra e biológicas. O compromisso com a interdisciplinaridade e a sustentabilidade é, portanto, a marcascientíficopolítica desta área que atualmente reúne 80 programas com mais de 100 cursos. O perfil do cientista da ACA também é caracterizado pela habilidade em fazer dialogar interesses, métodos e resultados de diferentes áreas do conhecimento na busca de soluções de problemas científicos e tecnológicos. Contudo, o pesquisador da área deve dedicarse aos problemas ambientais, que não se resumem a preservação e conservação de recursos. Os problemas ambientais são complexos porque envolvem elementos bióticos, abióticos e antrópicos; uma vez que todo meio ambiente se encontra hoje num gradiente de maior ou menor antropização, descartando-se praticamente a existência de ambientes puramente naturais. Além desta complexidade as soluções para os problemas ambientais devem se orientar pelos princípios da sustentabilidade, superando não apenas as diferenças disciplinares, mas também as distâncias entre a ciência e as demais formas de produção de saber não acadêmicas.

A partir destas definições emerge uma primeira conclusão, a de que a AI não elege um campo problemático específico como o ambiental ainda que não o exclua. A ênfase desta área está mais em sua abordagem e métodos do que no interesse por um problema comum. Ao contrário, a ACA tem o ambiente como seu problema natural e complexo, o que a compele necessariamente a adotar o caráter interdisciplinar. Assim, nos parece possível conduzir um estudo interdisciplinar sem tratar do ambiente, mas o contrário não é possível, não podemos pesquisar o meio ambiente fora do campo interdisciplinar. Neste sentido é coerente a criação de uma área que se volte especificamente para questões ambientais, que congregue diferentes disciplinas que colaborem de forma integrada. O compromisso com a sustentabilidade, evidenciado no documento que define a ACA, também traz uma conotação política clara e avessa à neutralidade científica. Nesta área, as ciências não são jamais puras ou desinteressadas; elas visam gerar soluções para toda ordem de problemas ambientais que, muitas vezes, foram gerados pelo próprio avanço tecnológico e científico. O desafio das investigações e intervenções conduzidas nos dos cursos de pós-graduação é, portanto, o de se articular com as demais fontes geradoras de conhecimentos, sejam eles científicos ou não, mas também com outros agentes e setores sociais. Por meio da interdisciplinaridade as ciências ambientais devem tornar produtivo o diálogo entre as disciplinas naturais e humanas, entre os saberes acadêmicos e sociais, na construção de soluções para os problemas ambientais atuais. 
PHILIPPI JR. e seus colaboradores (2013) adotam a expressão “problemática socioambiental” para enfatizar a interdependência entre aspectos sociais e naturais. Conforme os autores, a

"pesquisa sobre a problemática socioambiental diz respeito, fundamentalmente, ao reconhecimento da relação de interdependência entre sociedade e natureza. Consequentemente, é, por definição, um estudo que requer um enfoque interdisciplinar do relacionamento e da interdependência entre seres humanos e natureza" (p. 518).

Em acordo com esta visão, a ACA surge no contexto da "efervescência interdisciplinar" (p. 522), ela vem para mexer no "conforto disciplinar" (p. 524) e desacomodar o mundo acadêmico. Aqui a interdisciplinaridade não é vista como uma área de conhecimento, mas sim como uma forma de aproximação científica, como um modo de fazer ciência que envolve todas as áreas do conhecimento. Para Leff (2011),

"a interdisciplinaridade implica assim um processo de interrelação de processos, conhecimentos e práticas que transborda e transcende o campo da pesquisa e do ensino no que se refere estritamente às disciplinas científicas e a suas possíveis articulações." (p.311).

Segundo o autor, o interdisciplinar chama para fora das ciências, busca envolver outros atores e saberes na produção do conhecimento que se encontra assim revitalizado e impregnado de sentido. A ciência pode assim circular pela pesquisa, pelo ensino, mas também pela extensão, onde ela, via de regra, realiza a sua inserção social. Neste sentido, a interdisciplinaridade é uma autocrítica do conhecimento científico tradicional que fundamentou a nossa civilização moderna, para Leff (2011),

"essa civilização do conhecimento é, ao mesmo tempo, a sociedade do desconhecimento, da alienação generalizada, da deserotização do saber e o desencantamento do mundo (a sociedade dos poetas mortos; uma sociedade sem propósito, sem imaginação, sem utopia, sem futuro)" (p. 312).

É contra a pseudoneutralidade científica que a interdisciplinaridade se impõe, contra um pragmatismo que termina por desvalorizar o próprio processo de produção do conhecimento. $\mathrm{Na}$ área ambiental, entre alguns dos efeitos ideológicos que a abertura interdisciplinar visa combater estão o reducionismo ecologista e o funcionalismo sistêmico. Portanto, ao pensarmos nos temas ambientais, não podemos reduzir o homem ao indivíduo ou população biológica, não podemos pensar nas inter-relações sistêmicas como se elas existissem a priori sem um desenvolvimento histórico, não podemos tratar as complexas organizações socioambientais apenas em termos de fluxo de matéria e energia. Conforme Leff,

"para poder abordar a questão da interdisciplinaridade e orientar tanto estratégias de investigação e de formação como políticas ambientais e de desenvolvimento sustentável, deve-se reconhecer os efeitos das políticas econômicas atuais sobre a dinâmica dos ecossistemas e sobre as condições de vida das comunidades.” (2011).

Nesta abordagem está na ordem do dia a produção de uma racionalidade ambiental (p.322) que não apenas integre o conhecimento mas que também transforme o paradigma atual a partir da articulação entre saberes técnicos-científicos com aqueles produzidos fora do sistema acadêmico. Assim, o acadêmico egresso das ciências ambientais deve pesquisar e ensinar acerca desse complexo objeto científico que reconhecemos como meio ambiente, mas também deve estar preparado para intervir profissionalmente nos problemas ambientais reais que se colocam para a sociedade.

\section{Panorama Histórico do MDMRA/UESC E de SUA AVALIAÇÃO PELA CAPES}

Como vimos, a relação entre interdisciplinaridade e ciências ambientais é um tema de alta relevância e não temos a pretensão de exauri-lo neste momento. Alguns dos trabalhos citados neste artigo já o fazem com muita propriedade (cf. PHILIPPI JR et. Al, 2000). Trazemos esta discussão para nortear nossa reflexão acerca das mudanças práticas que decorreram da saída MDRMA/UESC da AI e da sua inclusão na ACA. O MDRMA/UESC, programa que será foco de nossas análises, foi iniciado em 1998 e faz parte do PRODEMA, que envolve demais universidades do Nordeste acima especificadas. Em sua definição trata-se de um

“programa interdisciplinar, interinstitucional e inter-regional (...) que tem, como objetivo maior, a qualificação de futuros tomadores de decisões para o exercício do planejamento e para a prática de uma forma de desenvolvimento no qual estejam harmonizados os seus objetivos sociais, ecológicos e econômicos, contribuindo para a reversão do quadro atual de subdesenvolvimento e de degradação ambiental progressiva da região Nordeste e do país." (UESC, 2015).

O MDMRA/UESC foi recomendado pela CAPES ao final de 1997 e teve seu início em 1998. Seu objetivo é

“contribuir para o desenvolvimento sustentável das regiões tropicais úmidas, especialmente a do Sudeste da Bahia, através da formação de profissionais altamente qualificados, com plena visão integrada das relações ambientais inerentes à concepção, planejamento, operacionalização e monitoramento do processo de desenvolvimento. Isso implica, consequentemente, também no fortalecimento da infra-estrutura regional de pesquisa, ensino e extensão para a dinamização das atividades de geração e disseminação de novos conhecimentos científicos e experiências relevantes sobre o assunto" (UESC, 2015).

Antes de se configurar como mestrado, o curso teve seu início como uma especialização, voltada para profissionais da área ambiental da região. No contexto da decadência da cultura cacaueira, devido principalmente à vassoura de bruxa, era urgente encontrar soluções que pudessem conferir uma nova dinâmica regional, em seus aspectos ambientais, sociais e econômicos. Assim percebemos em seu objetivo fundador uma missão principalmente voltada para os problemas locais por meio da produção de conhecimento científico e de sua aplicação, sempre norteada pelos princípios sustentáveis, da conservação dos recursos naturais e do incremento do desenvolvimento loca e regional. No início dos anos 90 houve o início de um curso de Mestrado em Meio Ambiente, criado e conduzido por um pequeno grupo de biólogos e agrônomos oriundos da Comissão Executiva do Plano da Lavoura Cacaueira (CEPLAC), entidade federal criada expressamente para o desenvolvimento tecnológico-científico da região voltada prioritariamente para a cultura do cacau. Este curso não prosperou, provavelmente pela ausência de um projeto diretor que desse sentido ao elenco variado de disciplinas que foram oferecidas muito em função das especialidades do grupo docente que o conduzia.

Finalmente em 1988 o MDRMA/UESC tem início, constituído por um núcleo duro formado por docentes doutores de procedência técnico-extensionista. Na UESC, que ainda se estruturava como universidade a partir da integração de faculdades privadas isoladas em Ilhéus e Itabuna, estes profissionais encontraram a oportunidade de desenvolver seus anseios na área científica com uma grande liberdade e autonomia. Este primeiro grupo de pesquisadores doutores das áreas naturais e sociais foi organizado pelo doutor em agronomia Max de Menezes, também oriundo da CEPLAC. Sua tarefa foi reunir interesses 
e oportunidades de formação para os profissionais da área ambiental da região que tinham diante de si o enorme desafio de diversificar a vocação econômica local por meio de atividades ambientalmente consequentes que preservassem a herança do cacau, florestas de Mata Atlântica relativamente preservadas pelo manejo tradicional de cabruca. Este manejo que cultiva o cacau no sombreamento do dossel florestal retira apenas a vegetação do sub-bosque criando uma paisagem de floresta relativamente protegida, ainda que consideravelmente transformada. Desse modo, apesar do histórico de intervenção humana com uma atividade de monocultura, nossa região ainda é um dos hotspots de biodiversidade do planeta e esta riqueza de recursos demandava por uma utilização planejada e sustentável (CEPF, 2001). Daí surge a necessidade de atualização e formação de profissionais locais para seu manejo e soluções de problemas, apoiados na produção de conhecimentos técnicos-científicos comprometido com a sustentabilidade, em seus aspectos biofísicos, sociais e econômicos.

Se em um momento inicial o MDMRA/UESC foi criado para a solução de problemas ambientais regionais, ao mesmo tempo ele foi também uma solução para docentes da UESC que precisavam realizar seus mestrados sem afastamento de suas atividades, o que contribuiu sobremaneira para a diversidade disciplinar dos discentes e de suas pesquisas. Contudo, como veremos, nem todos os egressos permaneceram na área ambiental, grande parte retornou aos seus nichos disciplinares de origem. Vale destacar também que a existência do MDMRA/UESC contribui para a efetivação da UESC, a partir da reunião e estadualização de faculdades isoladas de Ilhéus e Itabuna acima mencionada. De todo modo, esta vocação inicial profissional do MDMRA/UESC fez com que o curso assumisse um pouco tardia e lentamente seu perfil mais acadêmico, que se refletisse diretamente em publicações científicas conforme será discutido mais adiante. O MDMRA/UESC foi o primeiro programa de mestrado da UESC, convergindo pesquisadores de distintas áreas que se agregavam ao núcleo duro inicial, desse modo ele teve também a função de gerador/incubador de programas de mestrado mais específicos que atualmente absorvem pesquisadores de perfil mais acadêmico que, em sua maioria, atuaram inicialmente no MDMRA/UESC. Nesta dinâmica vários pesquisadores da universidade passaram pelo MDRMA/UESC em seus 17 anos de existência, o que gerou uma grande rotatividade docente no programa e que contribuiu para a oscilação de sua avaliação conceitual realizada pela CAPES (Figura 1). Os cursos de mestrado iniciados na UESC após a implementação do MDMRA/UESC foram Genética e Biologia Molecular em 2001, Zoologia em 2003, Produção Vegetal em 2004, Sistemas Aquáticos Tropicais em 2004, Ecologia e Conservação de Biodiversidade em 2008, Biologia e Biotecnologia de Microrganismos Biologia e Biotecnologia de Microrganismos em 2008 e mais recentemente o de Economia Regional e Políticas Públicas em 2013.

Os programas de mestrado e doutorado são continuamente avaliados pela CAPES, sobretudo no que diz respeito à sua produção científica, tomada como indicador de qualidade de suas pesquisas e de seu impacto na comunidade da ciência. Aspectos como inserção social têm sido cada vez mais considerados, mas ainda não têm expressão quantitativa importante. A partir de critérios comuns a todas as áreas do conhecimento os programas recebem uma qualificação que varia de 1 a 7 (CAPES, 2013b). Em nosso caso, desejamos compreender o que faz o MDMRA/UESC ser melhor ou pior avaliado pela CAPES desde sua fundação. Tendo iniciado com nota três e passado por nota quatro ele se encontra atualmente em três o que não faz do rebaixamento uma realidade, mas ascende o alerta para esta possibilidade caso não se invista na melhoria de seus indicadores de produção. Acreditamos que a dispersão e rotatividade de pesquisadores do MDMRA/UESC não é o único fator que explica o resultado das avaliações da CAPES e é nesta direção que a avaliação dos perfis dos egressos pode nos demonstrar o resultado do que foi feito até agora e indicar caminhos para a melhoria de sua qualidade. Se levarmos em consideração as notas dos demais cursos do PRODEMA constatamos que o MDRMA/ UESC é um dos dois que estão avaliados com a nota três, os demais, mesmo os mais recentes, têm nota igual ou superior a quatro.

Figura 1 - Cronologia do grau de avaliação do MDRMA/UESC pela CAPES e da criação dos outros cursos de mestrado na UESC

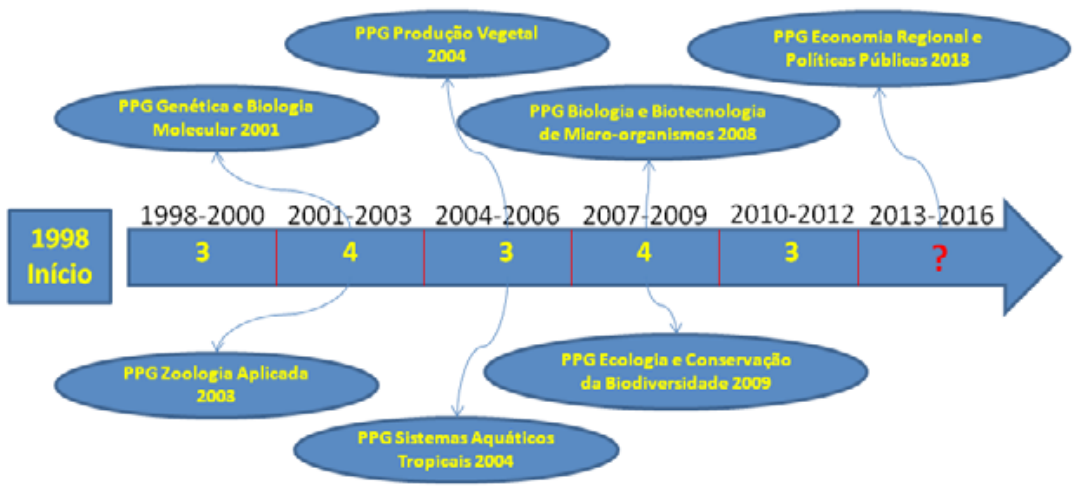

Fonte: Autores.

\section{Perfil de Egressos do MDMRA/UESC E de suas PUBLICAÇÕES}

Inicialmente procedemos à contagem de dissertações defendidas desde 2001 até dezembro de 2014 inclusive e obtivemos um total de 307. O currículo de cada um desses egressos foi pesquisado na plataforma Lattes do Conselho Nacional de Desenvolvimento Científico e Tecnológico (CNPQ) e, quando localizado, analisado em relação aos seguintes aspectos: área disciplinar de pertencimento, inserção acadêmica e profissional na área ambiental e publicações dos três anos seguintes à defesa de dissertação. Desse modo pudemos traçar o perfil do egresso do MDMRA/UESC. Destes 307 mestres egressos do MDMRA/UESC 228 ou 74,3\% não deram continuidade à formação acadêmica, 51 (16,6\%) estão cursando algum doutorado e apenas $28(9,1 \%)$ são doutores. Entre os 51 doutorandos 23 permaneceram no PRODEMA-UESC que teve seu doutorado iniciado em 2010, já tendo formado quatro doutores que também obtiveram seu título de mestre no mesmo programa. As grandes áreas de pertencimento disciplinar revelam um perfil de discentes oriundos, em sua maioria de graduados nas Ciências Sociais Aplicadas e em seguida nas Ciências da Vida.Tal fato indica que a abordagem interdisciplinar sempre imprimiu a dinâmica do programa, fazendo dialogar discentes e docentes em torno dos problemas ambientais, em seus aspectos biofísicos, sociais e econômicos, tanto em seus aspectos científicos como intervindo diretamente nos contextos que foram investigados pelos projetos de pesquisa orientados no programa. A grande variedade interdisciplinar 
se dá também no interior das grandes áreas, são 47 as graduações dos ingressantes (Figura 2). Apenas para citar as graduações mais presentes temos 51 das Ciências Biológicas, 35 da Geografia, 30 da Agronomia, 19 da Administração de Empresas, 18 do Direito e 16 da Enfermagem e nove da Comunicação Social. As demais 39 graduações estão representadas com menos de oito ingressantes cada uma.

Figura 2 - Grande área disciplinar de pertencimento dos ingressantes

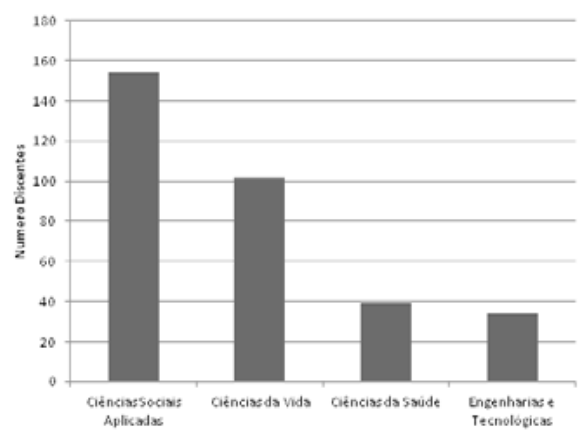

Fonte: Autores

A partir da análise individual dos currículos Lattes foi verificado que em relação à atuação no magistério, 129 (42\%) não tem carreira docente, $120(39,1 \%)$ são professores do ensino superior enquanto que $58(18,9 \%)$ atuam no ensino básico, a grande maioria no nível médio, sobretudo nos institutos técnicos, com somente dois atuando no ensino fundamental. Apenas um dos mestres formados pelo programa atua como professor e pesquisador no MDRMA/UESC obtendo seu doutoramento fora da UESC. Constatamos que na área do magistério o programa contribuiu para a capacitação dos docentes da região, tanto no nível superior como no médio, este último especialmente problemático. A presença de mestres em meio ambiente e desenvolvimento regional nas universidades, escolas e institutos profissionalizantes leva, ao menos como expectativa, a abordagem interdisciplinar para a educação das próximas gerações que retornam para suas atividades docentes preparados para a efetivação de uma educação ambiental permanente e da inserção da questão ambiental em projetos políticos-pedagógicos, grades curriculares e programas de disciplinas. Desse modo o MDMRA/UESC contribuiu e ainda contribui com o desenvolvimento regional no campo da educação, área especialmente sensível na região Nordeste (UNICEF, 2012).

Entre as atividades profissionais vinculadas à área ambiental e desempenhadas pelos egressos do MDMRA/UESC encontramos: secretários de educação e de meio ambiente, chefes de divisões ambientais de órgãos públicos, promotores de justiça, membros de conselhos deliberativos em e organizações não governamentais como fundações e institutos de ação socioambiental, assessores técnicos, consultores, auditores e analistas ambientais. Pudemos constatar que os egressos estão inseridos em funções profissionais tanto consultivas como deliberativas e executivas, seja no âmbito público ou privado. Esse perfil também contribui para o desenvolvimento regional com base nos princípios da sustentabilidade, por meio de agentes sociais capacitados tanto na identificação de problemas ambientais como na mobilização de diferentes setores e atores para a busca de suas soluções. Apenas para apontar alguns avanços regionais concretos, listamos as Unidades de Conservação (UC) conforme definidas pelo Sistema Único de Unidades de Conservação (SNUC) compreendidas no Território Litoral-Sul e que de modo direto ou indireto contaram com a participação de docentes, discentes e/ou egressos do MDRMA/UESC: Reserva Particular do Patrimônio Natural (RPPN) Fazenda Arte Verde em 1998 e RPPN Fazenda Araçari em 1998, Parque Nacional do Pau Brasil, RPPN Ecoparque de Una e RPPN Fazenda Sossego em 1999, RPPN Fazenda Paraíso em 2000, RPPN Pedra do Sabiá em 2001, RPPN Jueirana e RPPN Sapucaia em 2002, Área de Proteção
Ambiental (APA) Baia de Camamu em 2002, RPPN Fazenda Araraúna em 2003, RPPN Mãe da Mata e RPPN Rio Capitão em 2004, Reserva Extrativista (RESEX) de Canavieiras em 2006, RPPN Helico e RPPN Boa União em 2007, RPPN São José em 2008, Parque Nacional da Serra das Lontras em 2010 e RPPN Guanandi e RPPN Canto do Senhor em 2012 (ICMBIO, 2015). Devemos também destacar a criação desde 2013 da Base Ambiental Costa do Cacau que funciona como estrutura administrativa integrada entre a UESC e o Núcleo Mata Atlântica do Ministério Público (NUMA), abrigando as Promotorias Regionais Especializadas em Meio Ambiente de Ilhéus e Itabuna, o laboratório de análises e planejamento ambiental e os cursos de mestrado e doutorado em Ecologia. Ainda devemos levar em consideração a participação de docentes, discentes e egressos nos diversos comitês de bacias hidrográficos que de organizaram na região. Não podemos também deixar de mencionar a participação no curso dos profissionais da saúde que atuam no setor em instituições privadas e públicas, muitas vezes como gestores de políticas. Estes profissionais saem do MDRMA/UESC mais sensíveis e preparados para uma abordagem ambiental e coletiva da saúde, contribuindo também para o desenvolvimento regional.

Desse modo, os dados acima apresentados nos sinalizam que, caso a inserção social do MDRMA/UESC tivesse mais peso na sua nota de avaliação, ele seria mais bem qualificado. Infelizmente, a CAPES ainda não atribui um peso maior à contribuição dos cursos acadêmicos para o desenvolvimento regional. Acreditamos que tal postura não contempla a preocupação inicial da ACA com o problema do desenvolvimento, priorizando o impacto das publicações no âmbito acadêmico sem ainda ter desenvolvido mecanismos avaliativos das mudanças geradas em nível local, regional, nacional ou internacional, que resultaram em publicações. Em 2013, foi criado um grupo, pela Coordenação da ACA, para apresentar uma proposta de avaliação da inserção social. Nessa proposta, procurou-se avaliar as mudanças produzidas a partir da produção científica e dos projetos de extensão dos programas. Propunha-se, inclusive, que os projetos de pesquisa tivessem metodologia de avaliação dos impactos da pesquisa, em termos de mudanças geradas, como condição para que os órgãos de fomento concedessem recursos. Infelizmente, a proposta foi apresentada, mas ainda não surtiu nenhum impacto relevante na avaliação dos cursos. Acreditamos que sua efetivação possa provocar uma real mudança de paradigma no modelo de elaboração e financiamento dos projetos de pesquisa e de avaliação dos programas de pós-graduação.

Para a avaliação da produção científica consideramos apenas os egressos que defenderam suas dissertações até 2012 para que pudéssemos analisar as publicações em periódicos científicos no triênio seguinte à sua defesa. Sabemos que a análise da produtividade dos docentes e discentes é um elemento crucial para a avaliação do programa pelo peso que ganha na pontuação final, compondo $70 \%$ da nota. Desde 2002 a CAPES instaurou o sistema qualis de avaliação de periódicos, partindo do princípio que "dentro do conjunto de aspectos que caracterizam o desempenho dos mestrados e doutorados, a pesquisa e a consequente produção científica de docentes e alunos são considerados como os indicadores mais relevantes na determinação do padrão de qualidade dos cursos" (CAPES, 2002, p. 4). Atualmente, a lista da qualis da ACA se organiza a partir da lista de periódicos das publicações dos docentes, discentes e egressos dos cursos no último quadriênio, levando também em consideração o seu fator de impacto.

Em nossa avaliação, levamos em consideração a mudança de área de conhecimento do programa. Como indicamos antes, até o ano de 2011 o PRODEMA se encontrava na AI e a partir de então passou para a ACA. Foram então analisadas as produções científicas de 272 egressos que reuniram um total de 121 artigos, o que resulta em uma média de 0,44 artigos por cada um. Mesmo sem uma base comparativa consideramos esta média muito baixa, com menos de um 
artigo por dissertação, sobretudo quando constatamos que apenas 98 artigos têm seus periódicos qualificados nas listagens da ACA de 2015 e de 2014 e também na da AI de 2014, o que inevitavelmente indica um baixo impacto da produção científica do programa na literatura nacional e internacional (Figura 3). Quando observamos a cronologia das publicações temos uma enorme variação (Figura 4).

Figua 3 - Produção científica de egressos com defesa até 2012.

\begin{tabular}{|c|c|c|}
\hline Ano de Defesa & Publicações & $\begin{array}{c}\text { Publicações } \\
\text { Qualificadas }\end{array}$ \\
\hline $\mathbf{2 0 0 1}$ & 17 & 11 \\
\hline $\mathbf{2 0 0 2}$ & 5 & 4 \\
\hline $\mathbf{2 0 0 3}$ & 10 & 10 \\
\hline $\mathbf{2 0 0 4}$ & 8 & 8 \\
\hline $\mathbf{2 0 0 5}$ & 2 & 2 \\
\hline $\mathbf{2 0 0 6}$ & 3 & 2 \\
\hline $\mathbf{2 0 0 7}$ & 16 & 10 \\
\hline $\mathbf{2 0 0 8}$ & 16 & 14 \\
\hline $\mathbf{2 0 0 9}$ & 17 & 14 \\
\hline $\mathbf{2 0 1 0}$ & 11 & 11 \\
\hline $\mathbf{2 0 1 1}$ & 10 & 6 \\
\hline $\mathbf{2 0 1 2}$ & 6 & 6 \\
\hline TOTAL & $\mathbf{1 2 1}$ & $\mathbf{9 8}$ \\
\hline
\end{tabular}

Fonte: Autores.

Figura 4 - Distribuição cronológica das publicações de egressos com defesa até 2012

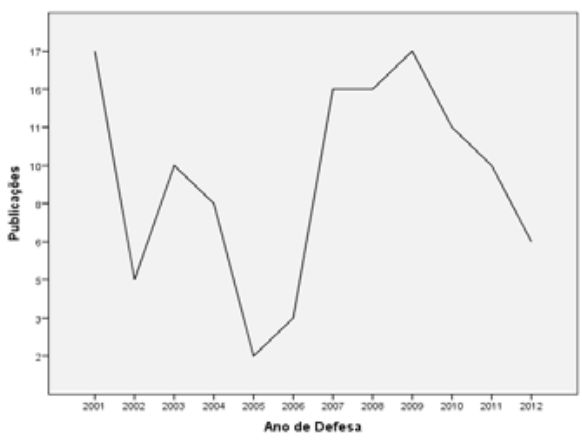

Fonte: Autores.

Para avaliação qualitativa da produção científica dos egressos adotamos a categorização da CAPES com B2+ para designar os periódicos qualificados como A1, A2 e B1 e B2- aqueles qualificados como B2, B3, B4, B5 e C (Figura 5). O que percebemos é uma queda na quantidade de artigos qualificados entre a AI e a ACA com o qualis de 2014, o que revela que a mudança ocorrida desde 2011 ainda não se reflete na produção acadêmica dos egressos, mas também na orientação docente dado que os artigos são produzidos sob supervisão e em colaboração com os orientadores. Quando comparamos a pontuação entre o qualis de 2014 e 2015 na ACA a queda é radicalmente expressiva, reflexo das mudanças recentes que são externas ao programa, mas que devem ser as referências norteadoras da sua produção acadêmica para que ele mantenha ou aumente a sua classificação na CAPES. Porém, devemos levar em consideração que, apesar da quantidade de artigos qualificados ter caído a sua qualidade foi levemente elevada já que conforme os critérios da ACA de 2014 os periódicos $\mathrm{B} 2+$ correspondiam a $23,61 \%$ da produção enquanto que conforme os de 2015 correspondem a $28,84 \%$.

Um dos fatores que podem ter contribuído para a baixa produtividade de artigos, sobretudo nos anos iniciais, foi a chegada tardia no MDMRA/UESC da corrida produtivista visando a avaliação dos programas de mestrado. Há duas décadas, em níveis nacionais e, sobretudo, regionais, o quantitativo de doutores era menor, o que gerava menos concorrência entre os currículos e menos pressão na cultura dos cursos no que se refere às publicações científicas, sobretudo naqueles com viés de inserção social. Apenas a partir de 2009 o MDMRA/UESC passou a exigir dos mestrandos o encaminhamento de artigos para periódicos científicos como condição de conclusão do curso. Podemos também perceber que o tempo para conclusão do mestrado foi limitado em 30 meses apenas a partir de 2010, o que conduziu a um maior volume de mestrandos e egressos e de potenciais publicações. Contudo, não podemos deixar de considerar que estes desafios se colocaram não apenas ao MDMRA/UESC, mas para todos os cursos de pós-graduação em ciências ambientais.

Figura 5 - Frequência e distribuição dos artigos publicados dos egressos com defesa até 2012 e qualificados por agrupamento de estratos

\begin{tabular}{|c|c|c|c|c|c|c|}
\hline \multicolumn{3}{|c|}{$\begin{array}{c}\text { Ciências Ambientais } \\
2015\end{array}$} & \multicolumn{2}{|c|}{$\begin{array}{c}\text { Ciências Ambientais } \\
2014\end{array}$} & \multicolumn{2}{|c|}{$\begin{array}{l}\text { Interdisciplinar } \\
2014\end{array}$} \\
\hline B2+ & 15 & $28,84 \%$ & 17 & $23,61 \%$ & 29 & $31,86 \%$ \\
\hline B2- & 37 & $71,16 \%$ & 55 & $76,39 \%$ & 62 & $68,14 \%$ \\
\hline TOTAL & 52 & $100 \%$ & 72 & $100 \%$ & 91 & $100 \%$ \\
\hline
\end{tabular}

Fonte: Autores.

\section{AplicaÇ̃̃o da matriz FOFA ao MDMRA/UESC}

A partir dos dados levantados podemos compreender as vulnerabilidades e ameaças ao MDMRA/UESC, bem como as suas forças e oportunidades conforme a matriz FOFA, ferramenta oriunda do setor empresarial e amplamente difundida para o aprimoramento de gestão e planejamento estratégico (Figura 6). A matriz busca individuar e interelacionar as Forças, Oportunidades, Fraquezas e Ameaças de uma dada situação ou instituição em relação ao seu ambiente. Trata-se de uma ferramenta transdisciplinar que busca clarear os cenários atuais em função de sua história e funcionamento visando o estabelecimento de metas futuras.

Consideramos o longo tempo de existência do MDRMA/ UESC, 17 anos, como uma de suas forças, a experiência acumulada criou uma cultura própria do curso, fiel a sua função de formar acadêmicos e profissionais comprometidos com o desenvolvimento da região. $\mathrm{O}$ apoio institucional também sempre viabilizou seu funcionamento, o MDRMA/UESC é valorizado internamente como um braço universitário que auxilia efetivamente a resolução de problemas ambientais regionais. Hoje temos além do mestrado um curso de doutorado que dá sequencia e aprofunda a formação dos cientistas ambientais. Atender à demanda social por meio da inserção de docentes e egressos nos desafios ambientais que se apresentam em uma região tão rica e vulnerável é também um de nossos pontos fortes. Por outro lado pudemos verificar que tanto docentes como discentes ainda não têm clareza de seu papel na avaliação do curso, o que reflete na baixa produção científica que é orientada mais por razões de cunho individual, geralmente os artigos oriundos das pesquisas desenvolvidas no MDRMA/UESC são encaminhados para periódicos específicos das disciplinas originárias dos pesquisadores sem a devida atenção ao quadro de qualificação da ACA. Outra fraqueza detectada foi a pouca inserção ambiental na instituição e em seus próprios problemas socioambientais que raramente são objeto de pesquisa e intervenção por parte do programa. Identificamos como ameaças a cada vez mais rigorosa escassez de recursos na educação nacional, especialmente para o ensino superior e os programas de pós-graduação. O recente decreto estadual de novembro de 2015 (BAHIA, 2015), além de efetuar um contingenciamento radical dos já parcos recursos disponíveis para a educação inviabiliza a realização de atividades que demandem por deslocamento de docentes e discentes, necessário sobretudo em um mestrado que faz parte de uma rede regional. A nova forma de elaboração da lista qualis que alterou seu conteúdo de forma radical também é uma 
ameaça a ser confrontada, bem como o risco de descredenciamento caso a próxima avaliação não nos seja favorável. Outro fator de risco consiste no modo como os concursos para docentes são estruturados, privilegiando candidatos com formação disciplinar específica e afastando os egressos de cursos interdisciplinares. Mesmo na UESC os editais de concurso não contemplam mestres e doutores com formação interdisciplinar. Como oportunidade identificamos uma possível mudança de área caso não sigamos credenciados ao PRODEMA. O ingresso de novos docentes já dispostos a investir na direção de melhora da pontuação do MDRMA/UESC é também uma oportunidade que se abre visando a avaliação que passou a ser quadrienal, o que nos dá mais tempo para incremento da produção. Como discutiremos a seguir a reestruturação do Programa de Pós-Graduação e da agregação de um mestrado profissional também se configuram como uma oportunidade para o MDRMA/UESC.

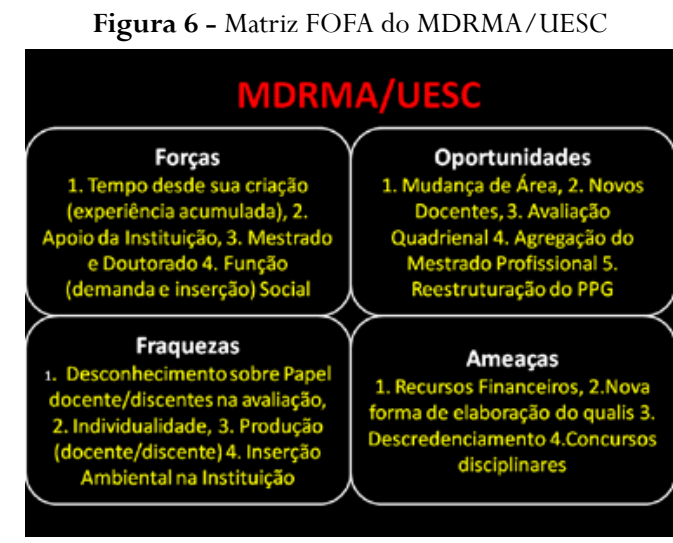

Fonte: Autores

\section{Perspectivas atuais e futuras}

Para o ano de 2016, quando será a próxima avaliação do MDRMA/UESC pela CAPES podemos vislumbrar diferentes cenários. O primeiro, pior e menos provável é a do rebaixamento $\mathrm{e}$ encerramento do curso. Atualmente há um esforço tanto de docentes como de discentes para incremento de publicações qualificadas visando uma boa avaliação pela CAPES. De fato, esse movimento de melhoria quantitativa e qualitativa de publicações já vem sendo estimulado pelos gestores nos últimos anos, mas tornou-se ainda mais enérgico diante da nova lista de periódicos qualificados já que muitos dos trabalhos já encaminhados foram submetidos a revistas que perderam em qualificação ou foram simplesmente subtraídas da ACA. Um segundo cenário é o de manutenção da nota três e de saída compulsória do PRODEMA que só renovará o credenciamento de cursos com nota igual ou superior a quatro. Se obtivermos um aumento de avalição para quatro se configura então um terceiro cenário de permanência no PRODEMA. Contudo, nossa avaliação interna revelou que o que sempre motiva mudanças no MDRMA/ UESC são demandas externas, oriundas da CAPES ou mesmo do PRODEMA, o que nos fez projetar um quarto cenário no qual integramos o mestrado e o doutorado em um mesmo programa independente e ofertamos também um mestrado profissional que pode ser uma fonte de recursos já que nesta modalidade a universidade pode cobrar pagamento de mensalidades. Seria uma forma de atender à especificidade do curso e também angariar recursos nestes tempos de cortes de verba na educação. Como programa independente poderíamos inclusive mobilizar a formação de uma rede com outros cursos voltados às ciências ambientais do Estado da Bahia.

Ficou também evidente a necessidade de uma postura mais proativa para estimular entre os mestrandos a sequência de sua carreira acadêmica, seja em sua área de origem ou na rede PRODEMA, bem como a sua inserção social. Como vimos $42 \%$ dos mestres não atuam na área acadêmica, mas ocupam funções estratégicas na rede social, o que lhes permite o exercício direto da uma racionalidade ambiental, no sentido dado por LEFF (2011), em seus locais de trabalho, onde geralmente ocupam função de consultores, gestores e técnicos. Desse modo o objetivo maior, de qualificar futuros e também os atuais, tomadores de decisões, seja em contexto acadêmico ou não, permanece em pauta. Neste cenário também teríamos a opção de retornar à AI ou permanecer na ACA a partir de uma avaliação interna do que seria mais conveniente e proveitoso.

No que diz respeito à produção de artigos, independente da área de vinculação na CAPES, estamos produzindo pouco. A produção de artigos deve ser cada vez mais estimulada, não sob uma ótica produtivista, mas como estratégia de divulgação das pesquisas realizadas e de fortalecimento dos currículos pessoais e do MDRMA/ UESC. Nesta direção podemos estimular a utilização nas disciplinas de artigos oriundos de periódicos listados no qualis da ACA, como forma de familiarização com os temas e linguagens que lhe são próprios e com pesquisas interdisciplinares. A adoção nas disciplinas de artigos em inglês também pode motivar a produção e envio para periódicos internacionais, aumentando assim as opções e chances de publicação. Outra solução a ser amadurecida é a substituição da dissertação por um artigo publicado, como já o fazem outros programas de pós-graduação. Este novo procedimento também contribuiria para a economia de recursos já que não seria necessária a formação de bancas com convidados externos que implicam em gastos com passagens e hospedagem, como também economizaríamos em consumo de energia, papel e insumos de impressão.

Devemos também levar em conta que uma parcela expressiva dos mestres $(18,9 \%)$ atua como docente no ensino básico, o que revela o importante papel e responsabilidade do MDRMA/UESC para a qualificação dos docentes deste segmento, sobretudo para a formação de educadores ambientais atuantes nas mais variadas disciplinas ofertadas pelos institutos técnicos e agrícolas federais da região. Aqui também vislumbramos o cumprimento de uma das missões das ciências ambientais, a de trabalhar em prol da sustentabilidade por meio da formação de profissionais capacitados para confrontar temas e problemas atuais. Porém, também vimos que apesar do MDRMA/ UESC ter contribuído para a cultura socioambiental regional, pouco ou nada foi feito em relação aos problemas ambientais de nossa própria universidade, fazendo valer o dito popular que afirma que em casa de ferreiro, espeto de pau. Certamente, a partir deste processo interno de avaliação, buscaremos conduzir pesquisas e intervenções nos problemas ambientais da UESC, como sistema de coleta de resíduos sólidos, proteção de seus remanescentes florestais e capacitação docente e discente para a educação ambiental.

Os problemas ambientais demandam por soluções, mas, sobretudo, por pessoas capazes de propô-las e implementálas, sempre com a participação de instituições ou setores sociais organizados. Fica claro que o egresso em ciências ambientais deve ser cientista e interventor, interdisciplinar, fluente na língua das ciências, mas, também nas línguas sociais e seus dialetos. A intredisiplinaridade deve sempre estar na ordem do dia, iniciativas de co-orientação entre pesquisadores de áreas e universidades diferentes devem ser estimuladas, proporcionado encontros simultâneos entre mestrandos orientadores e co-orientadores. Atualmente dispomos de tecnologia e meios de comunicação capazes de integrar pessoas e superar as distâncias que envolvem custos, ainda que as interações presenciais sejam sempre preferíveis.

De um modo geral, ter passado da AI para a ACA fez diferença em termos de pontuação de artigos, mas em termos conceituais 
não trouxe grande mudança, dado que toda ciência ambiental é necessariamente interdisciplinar e que todo desenvolvimento deve se pautar pela sustentabilidade. Ao revisitar a história do MDRMA/UESC e traçar o perfil de seus egressos e de suas publicações, vimos que a área socioambiental tem um grande peso no programa enquanto que na lista qualis da ACA os periódicos deste campo interdisciplinar são ainda poucos e mal qualificados em relação àqueles das ciências naturais e exatas. Nesta direção, seria interessante tornar o curso mais atraente para os pesquisadores destas áreas e principalmente estimular investigações com perfil mais tecnológico de modo a garantir um equilíbrio maior para a interdisciplinaridade do programa e de suas publicações. Como vimos, a lista da qualis da ACA se organiza a partir da lista de periódicos das publicações dos docentes, discentes e egressos dos cursos no último quadriênio. Desse modo, os cientistas ambientais se sentem pouco estimulados a enviar seus trabalhos a periódicos que não constem na lista ou são mal qualificados, provocando um enrijecimento do equilíbrio entre as áreas disciplinares que tende a reforçar a atual dominância de revistas das áreas naturais e o biocentrismo. A própria sistemática quantitativa de distribuição dos periódicos por estratos adotada pela CAPES impõe uma baixa classificação para a grande parte das revistas, independente de seus atributos próprios, dado que apenas um reduzido percentual delas caberá no estrato $\mathrm{A} 1 \mathrm{e}$ assim por diante. Um mesmo periódico classificado como $\mathrm{C}$ na ACA e, portanto, considerado como não relevante para a área pode em sua área específica como Educação ou Geografia ser classificada como A ou B. Este é um dos desafios futuros para aperfeiçoamento do sistema qualis de modo a atender às características próprias de uma área como ACA, interdisciplinar por natureza, mas que ainda hoje é submetida a critérios forjados para as disciplinas que resistem em preservar suas fronteiras. Acreditamos ser necessária uma profunda reflexão autocrítica por parte dos gestores acadêmicos de modo que nossos próprios mecanismos avaliativos não reproduzam a concentração de poder político/científico/editorial e não reforcem desigualdades, tendência que nos afasta cada vez mais dos princípios da sustentabilidade.

A reposta à nossa questão inicial que emerge deste esforço de avaliação do MDRMA/UESC é que não é necessária uma opção entre a formação de acadêmicos ou ambientalistas profissionais, a própria interdisciplinaridade inerente aos cursos de ciências ambientais, impõe esta dupla qualificação. Evocamos especialmenteWilson (1999), biólogo evolucionista que elegeu como campo de pesquisa o território minado entre ciências naturais e humanas, tendo sido muitas vezes estereotipado negativamente como biologicista, sobretudo pelos cientistas sociais críticos em relação a qualquer explicação que envolva a dimensão natural dos seres humanos. Ao trazer a consciliência do conhecimento como tarefa premente da ordem do dia na pauta acadêmica concordamos com o autor de que este esforço não é muito popular e que pode ser interpretado como "confusão, simplismo, reducionismo ontológico e cientificismo" (p. 10). A consciliência reúne as disciplinas e o saberes por elas produzidos e sistematizados, não se trata de um arranjo forçado de linguagens e métodos incompatíveis, mas consiste no esforço de fazê-los dialogar e construírem um sentido comum para além de suas fronteiras. Nas palavras do próprio autor, "a busca da consciliência pode parecer, à primeira vista, aprisionar a criatividade. O oposto é verdadeiro. Um sistema unificado de conhecimentos é o meio mais seguro de identificar os domínios ainda inexplorados da realidade. Fornece um mapa claro do que é conhecido e formula as perguntas mais produtivas para futura investigação" (p. 287). Esperamos ter lançado questões relevantes à avaliação de demais cursos do gênero que compartilham conosco dos mesmos dilemas acadêmicos e desafios colocados pelos mecanismos avaliativos da CAPES. Acreditamos que o autoconhecimento por parte dos programas de pós-graduação em ciências ambientais seja o primeiro passo essencial para melhor definição de suas prioridades e metas e para o fortalecimento e melhoria tanto de sua produção acadêmica como da assertividade de sua inserção social.

\section{REFERÊNCIAS}

BAHIA. 2015. Decreto $\mathbf{N}^{\mathbf{0}} \mathbf{1 6 . 4 1 7}$ de $\mathbf{1 6}$ de novembro de 2015. Disponível em http://www.ba.gov.br/arquivos/File/ DECRETON16417de161115CONTROLEDEGASTOS.pdf Acesso em 20/11/2015.

CAPES. 2013a. Documento de Área Interdisciplinar. Disponível em http://www.capes.gov.br/images/stories/ download/avaliacaotrienal/Docs_de_area/Interdisciplinar_doc_ area_e_comiss\%C3\%A3o.pdf Acesso em 28/09/2015.

CAPES. 2013b. Documento de Área Ciências Ambientais. Disponível em https://www.capes.gov.br/images/stories/ download/avaliacaotrienal/Docs_de_area/Ciencias_Ambientais_ doc_area_e_comiss\%C3\%A3o_block.pdf Acesso em 28/09/2015.

CAPES. 2002. Boletim Informativo, 10(2): 1-149.

CEPF. 2001. Mata Atlântica. Hot spot de Biodiversidade. Disponível em http://www.cepf.net/Documents/final.portuguese. atlanticforest.pdf Acesso em 22/09/2011. Acesso em 28/09/2015.

ICMBIO. http://www.icmbio.gov.br/portal/ Acesso em 24/09/2015.

Leff E. 2011. Complexidade, interdisciplinaridade e saber ambiental. Olhar de professor, 14(2): 309-335.

Philippi Jr. A, Sobral M, Fernandes V, Sampaio CAC. 2013. Desenvolvimento sustentável, interdisciplinaridade e Ciências Ambientais. RBPG, 10(21): 509-533.

Philippi Jr. A, Tucci CEM, Hogan DJ, Navegantes R. 2000. (Eds.), Interdisciplinaridade em Ciências Ambientais, São Paulo: Signus Editora, 319 p.

UESC. 2015. Mestrado em Desenvolvimento Regional e Meio Ambiente, Apresentação. Disponível em http://www. uesc.br/cursos/pos_graduacao/mestrado/mdrma/index. php?item $=$ conteudo_apresentacao.php. Acesso em 12/02/2015.

UNICEF. 2012. Acesso, permanência, aprendizagem e conclusão da Educação Básica na idade certa - Direito de todas e de cada uma das crianças e dos adolescentes, Brasília: UNICEF, $130 \mathrm{p}$.

Wilson EO. 1999. A Unidade do Conhecimento Consciliência, Rio de Janeiro: Campus, 321 p. 